\title{
Activación de la competencia complementaria de la Corte Penal Internacional en Colombia
}

\section{Activation of the complementary jurisdiction of the International Criminal Court in Colombia}

\author{
RUTH GARCÍA OTERO \\ Abogada, magíster en Asuntos Internacionales. Docente de la Facultad de Jurisprudencia \\ de la Universidad Autónoma del Caribe. \\ ruth.garcia@uac.edu.co
}

Recibido: Febrero 18 de 2012

Aceptado: Abril 20 de 2012

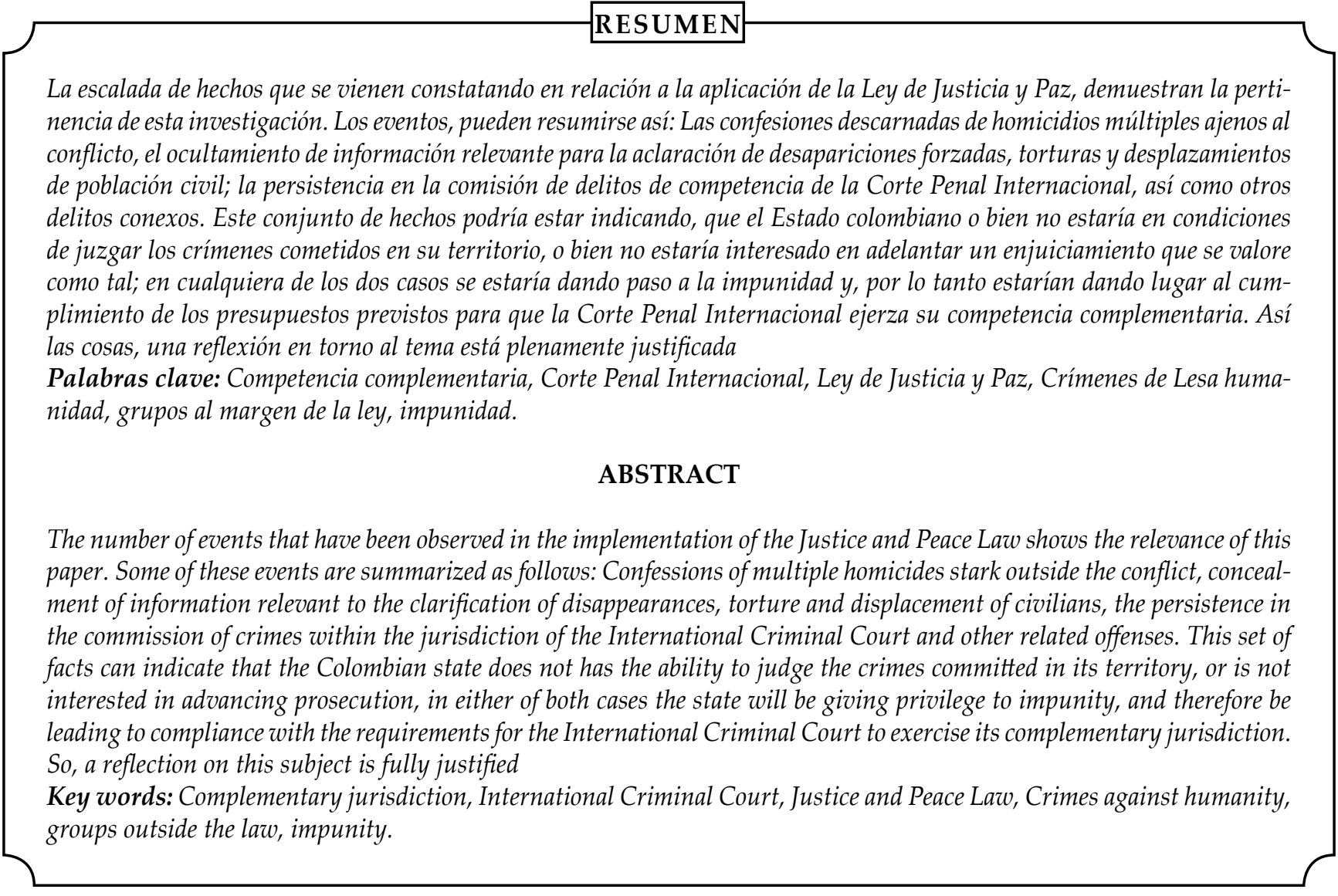


El día 2 de agosto del año 2002, el Gobierno colombiano, al ratificar el tratado que dio vida al Estatuto de Roma, mediante el cual se creó La Corte Penal Internacional, lo hizo acogiéndose a la disposición transicional prevista en el artículo 124 del Estatuto de dicho tribunal internacional introduciendo la declaración de que no aceptará - durante un período de siete años contados a partir de la fecha en que el Estatuto entrara en vigor respecto del Estado colombiano - la competencia de la Corte sobre la categoría de crímenes a los que se hace referencia en el artículo 8 (esto es, los crímenes de guerra), cuando se denuncie la comisión de uno de esos crímenes por sus nacionales o en su territorio. Según el gobierno de la época, se optó por acogerse a la cláusula de transición con el fin de facilitar eventuales procesos de paz con los grupos armados ilegales, especialmente con los grupos armados de izquierdas. Sin embargo, existen otras opiniones, según las cuales la cláusula de transición fue utilizada para proteger a los propios agentes del Estado, que directa e indirectamente intervienen en el conflicto interno colombiano. La no aceptación de la competencia de la Corte, empero, no se extiende a otros crímenes descritos en el artículo 5 del Estatuto de Roma, como, por ejemplo, los crímenes de lesa humanidad.

La situación actual del país, en lo referente a la Ley de Justicia y Paz, la desmovilización de grupos al margen de la Ley, en este caso especial de las llamadas Autodefensas Unidas de Colombia (AUC) y sobre el cual se limita este trabajo, obliga a que se plantee la siguiente cuestión: ¿Puede la Corte Penal Internacional atribuirse la competencia de investigar y juzgar los crímenes cometidos por los miembros de los grupos organizados al margen de la ley que hayan sido beneficiados por la Ley de Justicia y Paz? Una respuesta afirmativa a la pregunta es enteramente posible; en efecto, los procesos judiciales que se adelantan en contra de algunos de los jefes - contra los otros integrantes, en realidad los verdaderos autores materiales de los delitos, ni siquiera se ha previsto abrir un expediente - de los grupos paramilitares, parecen estar demostrando que los crímenes que se han cometido son de tal gravedad, que las penas con las que sancionan, resultarán ser meramente simbólicas; ello daría lugar a que la Corte Penal Internacional considere que el Estado colombiano no está dispuesto a llevar a cabo la investigación o juzgamiento en contra de los autores de tales hechos, y que los procesos seguidos en su contra solo han tenido el "propósito de sustraer a la persona de que se trate de su responsabilidad penal por crímenes de la competencia de la Corte", tal como lo señalan los artículos 17 y 20 del Estatuto del Tribunal Internacional; por lo tanto, encontraría cumplidos los presupuestos para la admisibilidad de la competencia complementaria que se le ha conferido; la activación de la competencia de la Corte podría producirse mientras se están adelantando los procesos en Colombia y también cuando estos ya han terminado ${ }^{1}$.

Así las cosas, una reflexión en torno al tema está plenamente justificada. La escalada de hechos que se vienen constatando en relación a la aplicación de la Ley de Justicia y Paz, relevan de mayores esfuerzos argumentativos tendientes a demostrar la pertinencia de esta investigación. Los eventos, por sí mismo evidentes, pueden resumirse del siguiente modo: Las confesiones descarnadas de homicidios múltiples - que no guardan relación con el conflicto armado interno - en diferentes lugares del territorio nacional; el ocultamiento de información relevante para la aclaración de desapariciones forzadas, torturas y desplazamientos de población civil; la persistencia en la comisión de delitos de competencia de la Corte Penal Internacional, así como otros delitos conexos; etc., son de conocimiento público tanto dentro del país, como fuera de él. Este conjunto de hechos podría estar indicando, que el Estado colombiano o bien no estaría en condiciones de juzgar los crímenes cometidos en su territorio, o bien no estaría interesado en adelantar un enjuiciamiento que se valore como tal; en cualquiera de los dos casos se estaría recorriendo la alameda de la impunidad $\mathrm{y}$, de contera, estarían dando lugar al cumplimiento de los presupuestos previstos para que la Corte Penal Internacional ejerza su competencia complementaria.

\section{Aproximación a los fundamentos para la acepta- ción estatal de una jurisdicción internacional}

Es evidente, por decir lo menos, que la aceptación, por parte de los Estado nacionales, de la existencia de una jurisdicción internacional va en contravía de la tradición ilustrada. Esto quiere decir que, para que este fenómeno ocurriera, ha tenido que verificarse un cambio de paradigma, jalonado por formulaciones teóricas o simplemente por la constatación de los hechos. A continuación se presentan algunas opiniones - que muy seguramente no estarán

\footnotetext{
Elartículo17delEstatutodelaCortePenalInternacional-enparticular, la parte final de su literal a), que establece que la competencia de la Corte será admisible cuando el Estado no “...esté dispuesto a llevar a cabo la investigación o el enjuiciamiento o no pueda realmente hacerlo". Además, con el numeral 3 del artículo 20 de dicho Estatuto, que establece, que "La Corte no procesará a nadie que haya sido procesado por otro tribunal en razón de hechos también prohibidos en virtud de los artículos 6,7 u 8 a menos que el proceso en el otro tribunal: a) Obedeciera al propósito de sustraer al acusado de su responsabilidad penal por crímenes de la competencia de la Corte; o b) No hubiere sido instruido en forma independiente o imparcial de conformidad con las debidas garantías procesales reconocidas por el derecho internacional o lo hubiere sido de alguna manera que, en las circunstancias del caso, fuere incompatible con la intención de someter a la persona a la acción de la justicia".
} 
exentas de objeciones - que, desde el especializado ámbito de la Teoría de las Relaciones Internacionales, tratan de explicar esta crucial cuestión.

Así, para Del Arenal (2005, p. 23-37)., si tuviera que hacerse una recapitulación de la situación de la Teoría de las Relaciones Internacionales en los últimos trescientos años - que no es sino el período coincidente con el de la tradición ilustrada -, tendría que afirmarse que desde el siglo XVII hasta una fecha que puede ser considerada reciente, el campo de estudio de las relaciones internacionales ha estado gobernado por un único paradigma o arquetipo; que en razón de este paradigma - denominado, en la actualidad, estatocéntrico, tradicional o realista ${ }^{2}$-, el análisis de las relaciones internacionales se hacían tomando como referentes incondicionales al Estado y al poder. Desde la configuración del sistema europeo de Estados, continúa Del Arenal (2005, p.24), es decir durante más de tres centurias, se experimentó una pacífica aceptación, tanto intelectual como científica, del paradigma tradicional, que terminó por limitar la perspectiva de la sociedad internacional, por fijar el pensamiento internacional, por guiar la investigación empírica y proporcionar respuestas a los problemas que planeaba la política internacional; desde este punto de vista, en el plano práctico, el norte que inspira la investigación lo constituye la seguridad nacional, pues al no existir un poder superior a los Estados, son ellos los que han de velar por su propia seguridad. Esta compacta interpretación científica de las relaciones internacionales sólo ha tenido aisladas singularidades aisladas, sin influencia efectiva - con la meritoria excepción del marxismo - en la teorización internacional. Una perspectiva semejante a la sostenida por Del Arenal, mantiene John Burton, quien al interrogante ¿Cuál es la naturaleza de ese elemento exterior que se ha constituido en materia de estudio de las relaciones internacionales?, contesta que ese elemento externo, independientemente de en qué consista, no es sólo de interés exclusivo de filósofos y teóricos, sino que comporta un particular interés práctico, dado que la política precisamente emana de las percepciones de la realidad, la cual está en permanente cambio, y que por su obviedad, releva de cualquier esfuerzo demostrativo. En torno a esta cardinal cuestión - la naturaleza del elemento exterior de las relaciones internacionales -, Burton asevera que "Las hipótesis tradicionales que atribuyen a los estados la categoría de actores principales, cuando no únicos,

2 Los postulados fundamentales del paradigma realista serían, para John A. Vásquez, los siguientes: “1) Las naciones-estados, son los actores más importantes en la comprensión de las relaciones internacionales. 2) Existe una distinción tajante entre política interna y relaciones internacionales. 3) Las relaciones internacionales son la lucha por el poder y la paz. El propósito de la disciplina es comprender cómo y por qué se gesta dicha pugna, y propone mecanismos de regulación de la misma. Toda investigación que no se relacione con este propósito, ni siquiera de manera indirecta, resulta trivial". (Vásquez, 2005. p. 141). implican también que el interés primordial de la política es la preservación de los estados y de sus instituciones, así como del sistema interestados y de sus instituciones. Reconocen a la ley y al orden impuestos por las autoridades estatales e interestatales como la condición necesaria para la estabilidad social y la convivencia pacífica dentro de y entre los estados. Tales hipótesis han logrado prevalecer, pese a que no han logrado producir políticas que permitan alcanzar los objetivos citados. No se ha podido refrenar la desviación a nivel social o interestados, tal como lo demuestran las crecientes cifras de criminalidad y las persistentes condiciones bélicas tanto interestados como intraestados" (Burton, 2005, pp. 128 y 129) La fuerza de estos hechos, opinan Del Arenal y Burton, ha forzado un desplazamiento del referente ilustrado para la Teoría de las Relaciones Internaciones hacia su antípoda, tal como se expone a continuación.

El primero de los autores nombrados sostiene que ya desde la culminación de la segunda gran conflagración mundial se ha verificado un acelerado cambio en la concepción de las relaciones internacionales, para la cual el paradigma estatocéntrico no ofrecía las respuestas apropiadas, pues el mundo se había tornado en una realidad más compleja y problemática; ante esta evidencia, dos nuevos paradigmas entraron a competir con el realista: El primero de ellos es el paradigma de la sociedad global o mundial, llamado también paradigma de la interdependencia, mientras que el segundo es el paradigma de la dependencia ${ }^{3}$. El paradigma de la sociedad global, que se formuló en los años setenta, no es realmente nuevo, sino que tiene una larga tradición; naciendo con los estoicos griegos y romanos, fue considerado por Kant (2005) como una exigencia de la razón'; lo realmente nuevo es que ya no se le considera

\footnotetext{
Sin restar importancia a esta propuesta teórica, por considerar que su formulación no se acomoda al camino seguido para aceptar la jurisdicción internacional, no se hará un desarrollo de este paradigma.

4 Immanuel Kant, en torno a la sociedad mundial, sostenía que "Los Estados con relaciones recíprocas entre sí no tiene otro medio, según la razón, para salir de la situación sin leyes, que conduce a la guerra, que el de consentir leyes públicas coactivas, de la misma manera que los individuos entregan su libertad salvaje (sin leyes), y formar un Estado de pueblos (civitas gentium) que (siempre, por supuesto, en aumento) abarcaría finalmente a todos los pueblos de la tierra. Pero si por su idea del derecho de gentes no quieren esta solución, con lo que resulta que lo que es correcto in thesi lo rechazan in hipothesi, en este caso, el raudal de los instintos de injusticia y enemistad sólo podrá ser detenido, en vez de por la idea positiva de una república mundial, por el sucedáneo negativo de una federación permanente y en continua expansión, si bien con la amenaza constante de que aquellos instintos estallen"...(y señalaba ya en su tiempo, algo que comúnmente acontece hoy en día, con el desarrollo de las comunicaciones, que)...Como se ha avanzado tanto en el establecimiento de una comunidad (más o menos estrecha) entre los pueblos de la tierra que la violación del derecho en un punto de la tierra repercute en todos los demás, la idea de un derecho cosmopolita no resulta una representación fantástica ni extravagante, sino que completa el código no escrito del derecho político y del derecho
} 
como una reclamación de la razón o una aspiración humanitaria o moral, sino una obligación impuesta por la situación existente en los tiempos que corren. Esta nueva situación es totalmente diversa a la dio lugar al paradigma estatocétrinco: En la actualidad existe una gran proliferación de organizaciones internacionales; la globalización de la vida en todos sus órdenes hace que todos los Estados sean interdependientes y que ya no dominen la política internacional; la seguridad nacional ya no constituye la preocupación primordial; por ello, estiman los defensores del paradigma de la interdependencia - que aunque no niegan que las relaciones internacionales son, por su esencia "problemáticas", afirman que tienen también un carácter cooperativo -, que el paradigma realista ya no tiene más vigencia. Del Arenal (2005), en un esfuerzo sintetizador, concluye que mirado el panorama internacional, de los años setentas del siglo pasado para acá, tiene que registrarse que "...uno de los más importantes cambios ha sido el debilitamiento del papel y significado del Estado, como entidad soberana y como estructura capaz de garantizar el bienestar y la seguridad de sus ciudadanos, y la aparición de nuevos actores, tanto intergubernamentales como no gubernamentales, de las relaciones internacionales, que, por su acción transnacional, tienden a limitar aún más el margen de maniobra de los Estados. El sistema internacional ha perdido, pues, el carácter estatocéntrico anterior" (Del Arenal p.32).

Burton, por su parte, sostiene que si se afirma que todas las interacciones que se realizan fuera y dentro de los Estados, están siempre bajo el control de una autoridad central ubicada dentro de las fronteras geográficas - es decir que toda interacción se da entre autoridades -, esta aserción no representa la realidad; ésta es muy diferente: No todas las interacciones que rebasan las fronteras de los Estados se verifican a través y bajo el control de las autoridades estatales; un concepto de sistemas que interactúan, sería más realista que un concepto de Estados interactuantes: Un sistema carece de barreras interactuantes. La interacción de los Estados, sostiene Burton, no es sino uno de los múltiples sistemas de interacción dentro de la sociedad mundial; el mapa de la sociedad mundial es una telaraña o red de interacciones. (Burton, pp. 130 y 131).

El paradigma de la sociedad global ha recibido fuertes críticas de los defensores del modelo clásico; sostienen que la Teoría de las Relaciones Internaciones desde el nuevo paradigma se torna retrógrada; que a un estudiante de política internacional se le imparta solamente una introducción a las técnicas de teoría de sistemas, de la ley de

de gentes en un derecho público de la humanidad, siendo un complemento de la paz perpetua, al constituirse en una condición para una continua aproximación a ella".(Kant, Traducción de Joaquín Abellán, 2005. pp.25, 26 y 30. las probabilidades, de la simulación o del análisis de contenido; con ello, advierten, el estudiante queda aislado del contacto con la materia, y no desarrolla ningún sentimiento hacia el funcionamiento de la política internacional o hacia los dilemas morales que ésta da origen. Expresan que si alguna luz ha arrojado el nuevo enfoque, ha sido cuando, traspasando sus límites, ha empleado el método clásico. Con ello, concluyen que:

“...Un futuro más probable para la teoría de la política internacional es que ésta permanecerá indefinidamente en el plano filosófico de debate continuo sobre los aspectos fundamentales (que las obras de los nuevos teóricos) no demostrarán ser una sólida subestructura sobre la cual pudiera construir la siguiente generación, sino más bien que aquellas que sobrevivan de algún modo tomarán su respectivo lugar al lado de trabajos anteriores, como guías inciertas y parciales hacia una materia esencialmente difícil de manejar; y que los sucesivos pensadores, en tanto que aprendan de lo que antes fue, continuarán sintiéndose impelidos a elaborar sus propias estructuras teóricas desde sus cimientos" ( Bull, 2005, pp. 114 y 115).

Puede observarse de la exposición que se ha realizado, que existe un vivo debate acerca del nuevo entendimiento de la Teoría de las Relaciones Internacionales; en virtud de ello, se considera que la fundamentación teórica para la aceptación, por parte de los Estados, de tribunales que ejerzan jurisdicción internacional, tiene el carácter de mera aproximación.

\section{La competencia internacional}

En forma análoga a lo que sucede con el concepto de competencia nacional, la competencia internacional también supone la existencia de la jurisdicción internacional.

Debe señalarse, empero, que en el ordenamiento jurídico internacional se suele utilizar indistintamente los términos "jurisdicción" y "competencia". Así, por ejemplo, el Estatuto que gobierna a la Corte Internacional de Justicia, en su Capítulo II, relacionado con su competencia, establece en su artículo 36 que "los Estados reconocen en cualquier momento la jurisdicción de la Corte en todas las controversias de orden jurídico..." Como es apenas evidente, cuando se enumeran los asuntos sobre cuales los Estados se obligan a la decisión de la Corte, se está haciendo referencia a la competencia y no a la jurisdicción, la cual - según se desprende del artículo - al parecer no se discute. Otro ejemplo, no menos diciente, en relación del trato indistinto que se está tratando, lo constituye el artículo 2 del Estatuto de la Corte Interamericana de Derechos Humanos: Este artículo se refiere, sin duda alguna, a la competencia de dicha Corte; 
sin embargo, en su numeral 1 expresa que "Su función jurisdiccional se rige por las disposiciones de los artículos 61, 62 y 63 de la Convención". Finalmente, debe hacerse mención al Estatuto de Roma de la Corte Penal Internacional, el cual, en su Preámbulo y en su artículo 1, establece que "la Corte Penal Internacional establecida en virtud del presente estatuto será complementaria de las jurisdicciones penales nacionales"; parece quedar claro que a lo que quiere hacer referencia el Estatuto es a la competencia, pues si se tratara de la jurisdicción, en sentido estricto, tendría que entenderse que también podría ejercerla, tratándose de un Tribunal con jurisdicción universal, para los delitos de hurto o de injuria, cuando estos no fueran juzgados por los tribunales nacionales. El trato indistinto empleado en las normas jurídicas internacionales, no obstante, no debe hacer perder de vista que la competencia internacional, tal como lo señalara Devis Echandia (1987) para los ordenamientos internos, está en una relación de especie a género con la jurisdicción internacional, y debe ser entendida como la potestad que tiene el tribunal internacional de conocer los concretos asuntos sometidos a su conocimiento. Esta cuestión tiene particular importancia cuando - como en el caso de la Corte Internacional de Justicia - la competencia prevista para una determinada jurisdicción no es clara, por no estar señalada en forma precisa ${ }^{5}$; no la tiene en cambio cuando los asuntos que debe conocer el Tribunal están claramente establecidos en su Estatuto ${ }^{6}$.

\section{La Jurisdicción de la Corte Penal Internacional}

La Corte Penal Internacional ejerce funciones jurisdicciones sobre las personas ${ }^{7}$ que hayan cometido los crímenes más graves de trascendencia internacional, de conformidad con su Estatuto fundacional, aprobado el día 17 de julio de 1998. Es un Tribunal que, a diferencia de sus antecesores - los Tribunales Penales Militares de Nuremberg y de Tokio, y los

5 El literal b) del artículo 36 del Estatuto de la Corte Internacional de Justicia, establece que tal Tribunal conocerá de "Cualquier cuestión de derecho internacional"; la indeterminación de la norma descrita, puede dar lugar a desconocer la competencia de la Corte, pero en ningún caso su jurisdicción.

6 Ejemplo paradigmático de ello, es el artículo 5 del Estatuto de Roma de la Corte Penal Internacional, cuando, en forma meridiana, expresa, en su numeral 1, que "La competencia de la Corte se limitará a los crímenes más graves de trascendencia para la comunidad internacional en su conjunto. La Corte tendrá competencia, de conformidad con el presente Estatuto, respecto de los siguientes crímenes: a) El crimen de genocidio; b) Los crímenes de lesa humanidad; c) Los crímenes de guerra; d) El crimen de agresión". Debe señalarse que el Estatuto es tan preciso en materia de competencia, al extremo de determinar cuando la Corte ejercerá competencia respecto del crimen de agresión.

7 Esta cuestión es una reafirmación de la responsabilidad penal individual internacional, que se ha venido acrisolando desde el establecimiento del Tribunal Militar de Nuremberg; se rompe así, en forma definitiva, con el entendimiento tradicional de que únicamente los Estados pueden ser internacionalmente responsables.
Tribunales Penales Internacionales ad hoc para la Antigua Yugoslavia y para Ruanda -, no tiene carácter provisorio, ni para un determinado territorio; no se ha instituido para juzgar a los responsables de crímenes ya cometidos antes de su creación; no tienen carácter militar, ni ha sido establecido por el Consejo de Seguridad de las Naciones Unidas, por motivos de urgencia. Por el contrario, es un Tribunal Penal de carácter permanente, con jurisdicción ecuménica, que solo juzgará a los responsables de crímenes cometidos con posterioridad a su entrada a vigor ${ }^{8}$ - el artículo 11 del Estatuto establece su competencia temporal ${ }^{9}$ y el artículo 24.1, una prohibición de retroactividad ratione personae, en el sentido de que "Nadie será penalmente responsable de conformidad con el presente Estatuto por una conducta anterior a su entrada en vigor" -, tiene carácter netamente civil y ha sido aprobado por Delegados Plenipotenciarios de la gran mayoría de países del mundo, en una discusión amplia que subsana el déficit democrático del que se le había criticado a sus antecesores. Estas cuestiones que los diferencian de sus antecesores, no aplacan, sin embargo, las críticas acerca del no cumplimiento, en forma esencial, del principio de legalidad; existen respetadas opiniones, como las de Vidales (2003) , que critican el empleo de términos que de por sí tienen implícita una gran carga valorativa, como por ejemplo el empleo del epíteto "grave", que acompaña a la mayoría de conductas que describen los artículos 6, 7 y 8 del Estatuto; con ello, sostiene, la tipificación habrá cumplido con una mera legalidad, pero de ninguna manera con la estricta legalidad que es connatural al principio nullum crimen sine lege (Vidales, 2003, p 199-218); o como la de Schünemann, para quien el artículo 28 del Estatuto de Roma contraviene el principio de culpabilidad y hace recordar prácticas de regímenes totalitarios (Schünemann, 2007. pp. 7 y 8$)^{10}$. La Corte Penal Internacional tiene como

8 Con arreglo al numeral 2 del artículo 126 del estatuto de Roma de la Corte Penal Internacional, tratándose de Estados que hayan ratificado, aceptado o aprobado el Estatuto o se adhieran a él, después de haberse completado las sesenta ratificaciones, aceptaciones, aprobaciones o adhesiones, para entrar en vigor, el Estatuto sólo entrará en vigor (para dichos Estados) el primer día del mes siguiente al sexagésimo día a partir de la fecha en que haya depositado su instrumento de ratificación, aceptación, aprobación o adhesión.

9 El numeral 1 del artículo 11 del Estatuto establece que "La Corte tendrá competencia únicamente respecto de crímenes cometidos después de la entrada en vigor del presente Estatuto" y su numeral 2 que "Si un Estado se hace Parte en el presente Estatuto después de su entrada en vigor, la Corte podrá ejercer su competencia únicamente con respecto a los crímenes cometidos después de la entrada en vigor del presente Estatuto respecto de ese Estado, a menos que éste haya hecho una declaración de conformidad con el párrafo 3 del artículo 12".

10 Este autor, en torno a esta importante cuestión, hace referencia específica a la disposición, contenida en el artículo 28 del estatuto, que sanciona "...al superior por un delito doloso, a pesar de haberse comportado apenas culposamente, de manera que en rigor es su estatus el que fundamenta su responsabilidad, y no su culpabilidad personal"; esta forma de imputación, afirma el autor citado, se corresponde más con un tipo de sociedad mágico-primitiva, que fun- 
sede la ciudad de la Haya (Países Bajos), está vinculada a las Naciones Unidas y entró en vigor el 1 de julio de 2002. El Estatuto, conforme a lo que establece su artículo 120, no admite ninguna clase de reservas en sus ratificaciones, aceptaciones, aprobaciones o adhesiones, aunque, como se verá más adelante permite que los Estados puedan acogerse al régimen de transición establecido en el artículo 124, única y exclusivamente en lo relacionado con los crímenes de guerra a los que se contrae el artículo 8 del Estatuto.

Siguiendo las normas establecidas en el ordenamiento jurídico colombiano, el Estatuto de Roma de la Corte Penal Internacional fue aprobado mediante la Ley 742 del 5 de junio de 2002; fueron declarados exequibles, tanto el Estatuto como su Ley aprobatoria, mediante Sentencia C-578/02 del 30 de julio de 2002 dictada por la Corte Constitucional el día, y expedido el instrumento de ratificación para ser ante el Secretario General de la Naciones Unidas el día 02 de agosto de 2002. En concordancia con lo anterior, el Estatuto entró en vigor para Colombia el día 1 de noviembre de 2002, de conformidad con el numeral 2 del artículo 126 del Estatuto de Roma de la Corte Penal Internacional.

\section{Competencia de la Corte Penal Internacional}

Siendo que la jurisdicción de la Corte Penal Internacional es ecuménica - territorialmente limitada, ciertamente, a los Estados que han ratificado, aceptado, aprobado o adherido al Estatuto -, su competencia está circunscrita, por mandato del artículo 5 que la rige, a cuatro crímenes, considerados los más graves de trascendencia para el conjunto de la comunidad internacional: a) El crimen de genocidio; b) Los crímenes de lesa humanidad; c) Los crímenes de guerra; $y$, d) El crimen de agresión. El Estatuto, además, advierte que sólo ejercerá competencia respecto del crimen de agresión cuando se apruebe una disposición, de conformidad con sus artículos 121 y 123, en la que se defina el crimen y se enuncien las condiciones en las cuales éstas serán enunciadas. Finalmente, se concluye que la competencia de la Corte Penal Internacional tiene el carácter de complementariedad con la de los Estados Nacionales, y para ser ejercida debe tenerse en cuenta lo previsto en los artículos 17 y 20 del Estatuto.

\section{Modalidades de activación de la competencia de la Corte Penal Internacional}

Las modalidades mediante las cuales la Corte Penal Internacional puede quedar habilitada para ejercer su competencia, están previstas en el artículo 13 de su Estatuto; en efecto, dicho artículo señala que la Corte podrá adquirir

dan la responsabilidad en la simple causación o en la pertenencia a un grupo o clan, y no al estado actual de nuestra cultura jurídica, que exige, como presupuesto para la imposición de una pena, la demostración de la culpabilidad. competencia para avocar el conocimiento de cualquiera de los crímenes tipificados en el artículo 5 del Estatuto, si se cumplen cualesquiera de los siguientes 3 requisitos de procedibilidad: a) Cuando uno de los denominados Estado Parte, hace la denuncia de una situación concreta ante el Fiscal - conforme al artículo 14 del Estatuto -, solicitando que se investigue si una o más de las infracciones definidas en el Estatuto como crímenes, han sido cometidas por una o varias personas determinadas. b) Cuando el Consejo de Seguridad de las Naciones Unidas, de conformidad con lo dispuesto en el Capítulo VII de la Carta de dicha Organización, envía la denuncia de una situación de un país, en que al parecer se ha cometido uno o varios de los crímenes tipificados en el artículo 5 del estatuto de la Corte. c) Cuando el Fiscal inicia una investigación en relación con un crimen tipificado en el artículo 5 del Estatuto, de conformidad con el artículo 15 del mismo; esta facultad del Fiscal está sujeta al control de la Sala de Cuestiones Preliminares ${ }^{11}$. Según sostiene Kaul (1999), la forma en que la Corte Penal Internacional puede adquirir la competencia, y el alcance de ella, se convirtió en "la cuestión de las cuestiones" durante todas las negociaciones, pues por su crucial importancia permaneció en el centro de la controversia hasta el final de la Conferencia de Roma, y sólo se llegó a la decisión final en el último día y en el último instante de la misma (Kaul, 1999. p. 214). Una atenta lectura de la segunda modalidad de activar la competencia de la Corte, debe llevarnos a concluir que está dirigida, sin duda alguna, a la situación de un país, en el que presumiblemente se hayan cometido o se estén cometiendo delitos cuyo conocimiento está asignado al conocimiento de la Corte Penal Internacional, siendo, en esta clase de sucesos, totalmente irrelevante de que se trate de un Estado Parte del Estatuto o no lo sea. Debe recordarse que el Capítulo de la Carta de la Organización de las Naciones Unidas, al que se hace mención, es el mismo que se invocó para el establecimiento de los Tribunales Penales Internacionales para la Antigua Yugoslavia y para Ruanda y que, en su oportunidad, fueron crudamente criticados por ser unos tribunales ex post factum (Álvarez, 2007. p. 426), por ignorar el principio nullum crimen sine lege y también por no tener un origen democrático. No obstante lo anterior, tratándose del Estatuto de Roma, esta norma puede hacer la diferencia de cara a la efectividad de la Corte; es decir entre su efectividad y su inefectividad; por ello, tiene una significación de primer orden. No debe inadvertirse, sin embargo, que la intervención del Consejo de Seguridad puede ser tanto para solicitar a la Corte una investigación, pero también para solicitar la suspensión no sólo de la investigación sino también del enjuiciamiento; en efecto, el artículo 16 del Estatuto así lo faculta; la suspensión, tanto de la investigación como del juicio, puede prolongarse

\footnotetext{
11 Este control se hace con arreglo a la "Regla 47: Testimonio en virtud del párrafo 2 del artículo $15^{\prime \prime}$.
} 
inclusive en forma indefinida, pues el artículo mencionado no establece límite a las solicitudes de renovación ${ }^{12}$. En torno a estas últimas cuestiones, resultan pertinentes los comentarios que hace Morten, con respecto a las palabras con las que Kofi Annan, en ese entonces Secretario General de la Organización de las Naciones Unidas, ${ }^{13}$ saludó la adopción del Estatuto de la Corte Penal Internacional en Roma, en el sentido de que

“...si la Corte va a operar de acuerdo a las más elementales expectativas de la comunidad internacional, es necesario que ella tenga competencia sobre las situaciones pertinentes, como también capacidad para investigar y juzgar casos en forma efectiva y justa...(pues, de un análisis inicial de los artículos 11 a 19 del Estatuto, en su opinión)...es cuestionable si la CPI tendrá capacidad de cumplir a cabalidad la promesa del Secretario General sin la continua intervención del Consejo de Seguridad como un socio activo al que le concierne la vigencia obligatoria internacional del derecho internacional humanitario" (Bergsmo, 1999. p. 182).

Además de las disposiciones contenidas en el artículo 13 del Estatuto, la adquisición de competencia por parte de la Corte, debe ser leída en concordancia con el artículo 12, en el que se establecen unas "condiciones previas para el ejercicio de la competencia". Así, el numeral 1 de tal artículo establece que el Estado que se convierta en Parte del Estatuto "acepta por ello la competencia de la Corte respecto de los crímenes a que se refiere el artículo 5". El artículo 5 del Estatuto, como ya quedó señalado, es el que registra el listado de los crímenes que, ratione materiae, es el objeto del conocimiento de la Corte. La doctrina, a esta condición previa para el ejercicio de la competencia, la llama "competencia inherente o automática", y debe entenderse como una limitación a todo intento de aceptación gradual de la competencia (Kaul, p. 218 y Bergsmo, p.183). Aledaña a la "competencia automática", está la llamada "competencia facultativa", que se refiere a las situaciones en las que un Estado no Parte del Estatuto, de acuerdo con el Estatuto de la Corte, acepte su competencia,

12 El artículo 16 del Estatuto establece: “Suspensión de la investigación o el enjuiciamiento. En caso de que el Consejo de Seguridad, de conformidad con una resolución aprobada con arreglo a lo dispuesto en el Capítulo VII de la Carta de las Naciones Unidas, pida a la Corte que suspenda por un plazo de doce meses la investigación o el enjuiciamiento que haya iniciado, la Corte procederá a esa suspensión; la petición podrá ser renovada por el Consejo de Seguridad en las mismas condiciones".

13 En la ceremonia de clausura de la Conferencia que adoptó el Estatuto de Roma de la Corte Penal Internacional, Kofi Annan, Secretario General de la Organización de las Naciones Unidas, calificó a la creación del Tribunal Internacional como "un obsequio a la esperanza de las futuras generaciones y un paso gigantesco en el camino hacia la vigencia universal de los derechos humanos y el imperio de la ley", además de considerarlo como "una hazaña que nadie hubiese creído posible, hace solo unos pocos años"( Bergsmo, 1999. p. 181). por estimar que en su territorio se haya cometido uno o varios de los delitos tipificados en el artículo 5 del Estatuto o el sospechoso de haberlo cometido sea nacional de dicho Estado no Parte (Pérez, 2003. p. 140). Debe señalarse, sin embargo, que esta limitación no es absoluta, pues el mismo Estatuto contempla, en su artículo 124, un disposición transitoria que constituye una relativización importante de la competencia automática, pues permite que los Estados no acepten, por un período de hasta 7 años, la competencia de la Corte sobre los crímenes de guerra ${ }^{14}$. Parece que tal disposición es el resultado de las tensas negociaciones - en las que no estaban ausentes ni el propósito de una rápida entrada en vigor del Estatuto, ni el de lograr apoyo para su propia aprobación ${ }^{15}$ - que tuvieron lugar en la Conferencia de junio-julio en la ciudad de Roma.

En el caso de Colombia, el gobierno del presidente Andrés Pastrana, en el momento de ratificar el Estatuto decidió acogerse a dicha disposición transitoria, con el fin de no cerrar las puertas a una posible negociación con los grupos armados al margen de la ley, particularmente para evitar que los integrantes de las guerrillas izquierdistas sean objeto de persecución por parte de la Corte, en razón de los crímenes que en contra del Derecho Internacional puedan cometer desde la ratificación del tratado hasta que se produzcan sus eventuales desmovilizaciones y su reinmersión a la vida civil. Paradójicamente, son sus an-

14 El texto de esta disposición transitoria, establece que "No obstante lo dispuesto en los párrafos 1 y 2 del artículo 12, un Estado, al hacerse Parte en el presente Estatuto, podrá declarar que, durante un período de siete años contados a partir de la fecha en que el estatuto entre en vigor a su respecto, no aceptará la competencia de la Corte sobre la categoría de crímenes a que se hace referencia en el artículo 8 cuando se denuncie la comisión de uno de esos crímenes por sus naciones o en su territorio. La declaración formulada de conformidad con el presente artículo podrá ser retirada en cualquier momento. Lo dispuesto en el presente artículo será reconsiderado en la Conferencia de Revisión que se convoque de conformidad con el párrafo 1 del artículo 123".

15 Frank Jarasch, quien participó en la Conferencia Diplomática de Plenipotenciarios de las Naciones Unidas, en Roma, como parte de la delegación alemana, consigna que la parte relacionada con las "Disposiciones finales", aparecieron solamente en el documento final de la Conferencia, distribuido en el último días de la Conferencia, y que se votó como un todo. Señala Jarasch "que estas disposiciones nunca se discutieron en alguna sesión del Comité en Pleno o por el grupo de trabajo "Cláusulas Finales". Su inclusión en el documento L.76 (del 16 de julio de 1998) fue una sorpresa para muchas delegaciones" (expresión entre paréntesis fuera de texto). Frank Jarasch, refiere que tal propuesta no era la que Alemania prefería, pero que la aceptó por que sirvió para ganar apoyo de otros Estados para el Estatuto. Concluye este autor aseverando que "Muchos miembros de la Unión Europea inicialmente fueron reacios a aceptar un régimen de transición semejante. Sin embargo, para ganar el apoyo francés al estatuto, muchos de ellos indicaron que podían admitir una exención limitada sólo para crímenes de guerra del estatuto, para aquellos países que hicieran una declaración al respecto". ( Jarasch, 1999. p. 176 y 177). 
típodas - los grupos paramilitares de derechas - quienes pretenden salir beneficiados con la declaración hecha al amparo de la disposición transitoria, pues son ellos quienes se encuentran llevando a cabo un proceso de negociación y desmovilización.

\section{Presupuestos para la activación de la competencia com- plementaria de la Corte Penal Internacional}

La competencia complementaria de la Corte - en este trabajo ya se ha hecho la precisión de que la denominación "jurisdicción complementaria" que se ha consignado en el Estatuto es incorrecta - está establecida en el décimo párrafo del Preámbulo del Estatuto de la Corte ${ }^{16}$ y en el artículo 1 del mismo ${ }^{17}$ y se encuentra desarrollada en el artículo 17 - el que establece las condiciones o presupuestos que deben reunir los asuntos para que su conocimiento sea admitido por la Corte ${ }^{18}$ - y en el artículo 20 - que prescribe

16 El párrafo 10 del Preámbulo del Estatuto, señala que Los Estados Partes en el presente Estatuto: "Destacando que la Corte Penal Internacional establecida en virtud del presente Estatuto será complementaria a las jurisdicciones penales nacionales".

17 El artículo 1 del Estatuto, bajo el epígrafe de "La Corte", establece que "Se instituye por el presente una Corte Penal Internacional ("la Corte"). La Corte será una institución permanente, estará facultada para ejercer su jurisdicción sobre personas respecto de los crímenes más graves de trascendencia internacional de conformidad con el presente Estatuto y tendrá carácter complementario de las jurisdicciones penales nacionales. La competencia y el funcionamiento de la Corte se regirán por las disposiciones del presente estatuto".

18 El artículo 17 del Estatuto - se transcribe, pese a su extensión, por ser de interés para los propósitos de este trabajo - bajo el título de "Cuestiones de admisibilidad", regula, en forma clara, la complementariedad de la competencia, del siguiente modo: "1. La Corte teniendo en cuenta el décimo párrafo del preámbulo y el artículo 1, resolverá la inadmisibilidad de un asunto cuando: a) El asunto sea objeto de una investigación o enjuiciamiento en el Estado que tiene jurisdicción sobre él salvo que éste no esté dispuesto a llevar a cabo la investigación o el enjuiciamiento o no pueda realmente hacerlo; b) El asunto haya sido objeto de investigación por el estado que tenga jurisdicción sobre él y éste haya decidido no incoar acción penal contra la persona de que se trate, salvo que la decisión haya obedecido a que no esté dispuesto a llevar a cabo el enjuiciamiento o no pueda realmente hacerlo; c) La persona de que se trate haya sido ya enjuiciada por la conducta a que se refiere la denuncia y la Corte no pueda incoar el juicio con arreglo a lo dispuesto en el párrafo 3 del artículo 20; d) El asunto no sea de gravedad suficiente para justificarla adopción de otras medidas por la Corte. 2. A fin de determinar si hay o no disposición a actuar en un asunto determinado, la Corte examinará, teniendo en cuenta los principios de un proceso con las debidas garantías reconocidos por el derecho internacional, si se da una o varias de las siguientes circunstancias, según el caso: a) Que el juicio ya haya estado o esté en marcha o que la decisión haya sido adoptada con el propósito de sustraer a la persona de que se trate de su responsabilidad penal por crímenes de la competencia de la Corte, según lo dispuesto en el artículo 5; b) Que haya habido una demora injustificada en el juicio que, dadas las circunstancias, sea incompatible con la intención de hacer comparecer a la persona de que se trate ante la justicia; c) Que el proceso no haya sido o no esté siendo sustanciado de manera independiente o imparcial y haya sido o esté sustanciado de forma en que, dadas las circunstancias, sea incompatible con la intención de hacer comparecer a la persona de que se trate ante la justicia". la materia relacionada con la cosa juzgada ${ }^{19}$ - de ese mismo cuerpo normativo.

En lo relacionado con la regulación contenida en el artículo 17 deben hacerse las siguientes consideraciones: El primer numeral del artículo tiene como eje la definición de si el Estado nacional, con competencia para investigar y juzgar a los presuntos responsables de haber cometido alguno o varios de los delitos descritos en el artículo 5 del Estatuto de la Corte, está o no dispuesto a investigarlos y juzgarlos y, además, si tiene o no el poder real de hacerlo. Si del examen que se haga la Corte concluye que tanto la disposición y el poder real concurren, se deberá preferir la competencia de los tribunales nacionales; si aconteciera lo contrario, la competencia corresponderá a la Corte. La carga de la prueba corresponde al Fiscal de la Corte y una decisión a favor de la competencia de la Corte estará, seguramente, sujeta a los recursos respectivos por parte del Estado examinado. La falta de disposición de los Estados nacionales - cuyas reglas para determinarlo están establecidas en el numeral 2 del artículo en estudio -, es decir la falta de voluntad, de someter a investigación y juicio a los presuntos responsables se determina valorando tres situaciones, bien sea conjunta o alternativamente. Bergsmo afirma, en torno a esta capital cuestión, que "El examen sobre la "disposición" de la justicia nacional a llevar o no el caso tal y como aparece en el artículo 17.2 es un examen sobre la buena fe de las respectivas autoridades nacionales" (Bergsmo, pp. 203 y 204.), proponiendo que el examen sobre la disposición debe encargarse a un cuerpo de magistrados ad hoc, para no comprometer la posición de los magistrados de la Corte que conocerían del asunto, en caso de ser comprobada la falta de disposición. Debe hacerse mención, en este punto, a la cuestión de las amnistías; es preciso advertir que el Estatuto de la Corte no prevé disposiciones en relación con la amnistía; podría presentarse, entonces, la situación planeada por Santalla, en el sentido que "La aplicación de una ley de amnistía - de iure - podría constituir un ejemplo de la decisión de un Estado de no perseguir un determinado crimen de competencia de la CPI, y podría

19 El artículo 20, bajo la rúbrica de "Cosa juzgada”, prescribe: "1. Salvo que en presente Estatuto se disponga otra cosa, nadie será procesado por la Corte en razón de conductas constitutivas de crímenes por las cuales ya hubiese sido condenado o absuelto por la Corte. 2. Nadie será procesado por otro tribunal en razón de uno de los crímenes mencionados en el artículo 5 por el cual la Corte ya le hubiere condenado o absuelto. 3 . La Corte no procesará a nadie que haya sido procesado por otro tribunal en razón de hechos también prohibidos en virtud de los artículos 6, 7 u 8 a menos que el proceso en el otro tribunal: a) Obedeciera al propósito de sustraer al acusado de su responsabilidad penal por crímenes de la competencia de la Corte: o b) No hubiere sido instruido en forma independiente o imparcial de conformidad con las garantías procesales reconocidas por el derecho internacional o lo hubiere sido de alguna manera que, en las circunstancias del caso, fuere incompatible con la intención de someter a la persona a la acción de la justicia". 
connotar una falta de intención o voluntad, conforme al artículo 17.1.a. En efecto, si se considera que el propósito de una ley de amnistía es liberar a determinadas personas de su responsabilidad penal, ésta tiene un efecto inherente e inmediato respecto a la investigación, el procesamiento y/o la ejecución de la sentencia del individuo en concreto, sea que existan o no otros fines que motiven la declaratoria de amnistía. Por tanto, esta situación podría enmarcarse en el caso del artículo 17.1.a y/o 17.2.a y constituir un caso admisible para la CPI" (Santalla, 2007. pp. 108 y 109). A su turno, el análisis de una eventual falta de poder real del Estado, para adelantar la investigación y el juicio, debe también encargarse a jueces ad hoc, pues, en la medida que implica la valoración de todo el sistema penal del Estado nacional examinado, la legitimidad de los magistrados titulares de la Corte que conocieran de los hechos - en caso de acreditarse la incapacidad o ausencia de poder real - estaría seriamente amenazada.

La disposición que regula la cosa juzgada ${ }^{20}$ está en relación estrecha con el artículo 17, acabado de analizar, pues ambos tratan de la adminisibilidad de la competencia; es más, el literal b) del numeral 1 del artículo 17 remite en forma expresa al numeral 3 del artículo 20. Además, el literal a) del numeral 2 del artículo 17 se refiere a la misma cuestión que lo hace el literal a) del numeral 3 del artículo 20: Que la decisión se haya tomado o el proceso se haya llevado a cabo con el propósito de sustraer a la persona de su responsabilidad penal o que los procesos se hayan llevado sin la observancia de las garantías procesales reconocidas por el derecho internacional. Análogamente al caso del artículo 17, la comprobación de esta presunta conducta reprobable de los Estados es un juicio sobre la buena fe de los mismos - que ciertamente remite al principio denominado pacta sunt servanda ${ }^{21}$ establecido en el artículo 26 de

20 La cosa juzgada es un principio de derecho procesal, por el cual se entiende, que una vez decidido, con el lleno de formalidades legales, un litigio o un asunto entre determinadas partes y en relación con unos hechos también determinados, tales partes deben acatar la resolución que la concluye, sin que les sea permitido plantearlo de nuevo; los jueces, a su vez, están en la obligación de respetarla.

21 El entendimiento que del principio pacta sunt servanda se tiene, en el sentido que los contratos deben ser cumplidos de buena fe, ha sido acremente criticado por autores como Carl Schmitt; este autor sostiene que "El postulado pacta sunt servanda enuncia que es posible obligarse jurídicamente por medio de los pactos. Hoy eso es algo evidente, y no constituye ni una norma, ni el fundamento moral de la validez de las normas. Antes bien, o es una completa duplicación e hipóstasis tautológica, o enuncia que el pacto concreto no vale, sino tan sólo la "norma" general de que los pactos valen. Adicionar a cada norma en vigor la "norma" de que los pactos en general son válidos, es una vacua ficción, pues el pacto concreto vale y obliga jurídicamente por virtud del derecho positivo y no por virtud de la norma pacta sunt servanda"( Schmitt, Carl., 1970. p. 79).

A su turno, Kelsen, sin hacer la crítica áspera de Schimitt, advierte que las normas del derecho internacional general obligan y facultan a todos los Estados; agrega que entre tales normas "...tiene especial significación la norma que corrientemente se expresa con la fórmula la Convención de Viena sobre el Derecho de los tratados ${ }^{22}$ -. Tal conducta tiene que valorarse teniendo en cuenta las experiencias registradas, sobre todo, en el cono sur del continente americano, en donde, al parecer, se llevaron a cabo procesos simulado y, en no pocos casos, se decretaron amnistías en forma indiscriminada, con el propósito de hacer que los autores de la violación grave de derechos humanos queden cobijados legalmente con el manto de la impunidad; sin olvidar, sin embargo, que para esa época no existía aún un Tribunal Penal Internacional. En punto de la cosa juzgada, González y Gorriz (2003), después de señalar que en la versión inglesa del Estatuto el principio está titulado como "ne bis in idem", hacen la distinción entre dos vertientes del principio: una material, que consiste en la prohibición de castigar dos veces el mismo hecho, y una procesal, que radica en la prohibición de ser sometido a dos procesos penales por el mismo hecho; indicando que esta distinción tiene especial importancia para eventos de los concursos de leyes y de delitos. A juicio de los autores citados, en el proceso penal ante la Corte Penal Internacional rige la vertiente procesal del ne bis in idem, dado que "es notoria la ausencia de criterios materiales para proscribir la duplicidad de sanciones por el mismo ilícito, es decir, la carencia de referencia expresa a la vertiente material del ne bis in idem" (González, y Gorriz, 2003. pp.225, 226 y 227).

\section{Análisis de los presupuestos para la activación de la com- petencia complementaria de la Corte Penal Internacional}

La competencia complementaria de la Corte Penal Internacional solamente podrá activarse si se cumplen los presupuestos establecidos en los artículos 17 y 20 de su Estatuto. El primero referido a las cuestiones de admisibilidad y el segundo a las excepciones al instituto jurídico de la cosa juzgada. Siendo así las cosas, la reflexión debe orientarse a la siguiente constatación: ¿En el proceso de desmovilización de los grupos paramilitares, antes y después de la vigencia de la Ley 975 de 2005 - pero después del 1 de noviembre de 2002, en que el Tratado entró en vigor en relación con el Estado colombiano -, se presentan algunos de los supuestos previstos en las aludidas normas del Estatuto de Roma? De lo que se trata, dicho de otra manera, es de constatar si el Estado colombiano está o no dispuesto a llevar a cabo la investigación y/o el enjuiciamiento de los delitos que también son de competencia de la Corte o, en su caso, si puede o no realmente hacerlo; que si ya hubo juicio, si la decisión fue adoptada con el propósito de sustraer a la

pacta sunt servanda. La misma faculta a los sujetos de la comunidad internacional a regular su comportamiento recíproco, es decir, a regular mediante tratados el comportamiento de sus órganos y de sus súbditos con respecto de los órganos y súbditos de los otros Estados".(Kelsen, 2003)

22 Art. 26. Pacta sunt servanda: "Todo tratado en vigor obliga a las partes y debe ser cumplido por ellas de buena fe". 
persona de que se trate de su responsabilidad penal por crímenes de la competencia de la Corte; que haya una demora injustificada en el juicio que, dadas las circunstancias, sea incompatible con el fin de hacer comparecer a la persona de que se trate ante la justicia; o que, si ya hubo juicio o éste esté en curso, el proceso no haya sido o no esté siendo sustanciado de manera independiente o imparcial y haya sido o esté siendo sustanciado de forma en que, dadas las circunstancias, sea incompatible con la intención de hacer comparecer a la persona de que se trate ante la justicia conforme al artículo 17 del Estatuto de la Corte -. Asimismo, y conforme al artículo 20 del referido Estatuto, en caso que ya hubieran procesos concluidos, de constatar que estos hubieran obedecido al propósito de sustraer al acusado de su responsabilidad penal por crímenes de la competencia de la Corte, o no hubieren sido instruidos en forma independiente o imparcial de conformidad con las garantías procesales reconocidas por el derecho internacional o lo hubiere sido de alguna manera que, en las circunstancias del caso, fuere incompatible con la intención de someter a la persona a la acción de la justicia.

Un examen desprevenido del modo como se ha producido el proceso de desmovilización, y la consiguiente aplicación de la Ley 975 de 2005, conduce a comprobar las siguientes cuestiones:

Desde los primeros contactos entre el gobierno nacional y los grupos paramilitares ha podido observarse una ausencia absoluta de transparencia; para la sociedad colombiana no ha estado claro bajo qué términos se producían las publicitadas, parciales y hasta pintorescas desmovilizaciones. La sensación que se causaba era que la desmovilización de cada grupo estaba precedida de una suerte de concesiones por parte del Estado, no declaradas por el gobierno, mucho menos por los irregulares. Esta anómala situación, tuvo su correlato en que los paramilitares escogieron su propio lugar de concentración; este lugar - Santa Fe de Ralito - estaba custodiado, ciertamente, por las fuerzas del Estado, pero no es menos cierto que de él podían salir cuando les placiera, tal como quedó demostrado con la "fuga" del irregular apodado "Adolfo Paz" o "Don Berna". Si tenían facilidades para "fugarse", es lícito concluir que también podían seguir violando la ley desde dicho centro de concentración. Tal aserto parece tener sustento en el homicidio del que fue víctima un político de la zona, durante la campaña electoral de 2006, en los contornos de Santa Fe de Ralito. Pero si estas cosas acontecieron, pareciera que el proceso de desmovilización era controlado por los paramilitares $y$, como es apenas natural, su objetivo no era precisamente comparecer ante la justicia; a su vez, la actitud pusilánime del gobierno solo podría tener explicación en su falta de disposición para llevar a cabo la investigación y el enjuiciamiento de los delitos cometidos o, en su caso, porque no podía realmente realizar ninguna de las dos funciones anotadas; la primera hipótesis parece tener mayor probabilidad de certeza.

Conjuntamente con lo anterior debe señalarse que en las plurales desmovilizaciones parciales no se otorgó ninguna importancia a la individualización e identificación reales de las personas que se desmovilizaban - esto es, de una gran parte de la tropa -, pues solamente se les "identificó" con el alias con el que se les conocía dentro de la organización delictiva; tampoco se tomó el trabajo de identificar las armas que los irregulares entregaban. La falta de identidad de unos y otras imposibilita llevar a cabo la investigación y juzgamiento de las conductas delictivas que, probadamente, cometieron los que en las aludidas ceremonias se desmovilizaron. De ninguna manera puede ser de recibo la justificación que las explicaciones entorno a los delitos las darían los jefes paramilitares que estaban concentrados, pues ello pasa por alto que la atribución de responsabilidad penal es personal; además, que una justicia selectiva - si es que se verificara en los jefes paramilitares - estaría violando el principio de igualdad, que es de la esencia del Estado de Derecho. Resulta en extremo problemático afirmar que las omisiones, a las que se hace referencia, se hayan producido en forma accidental, no deliberada; esto sería tanto como aceptar que el proceso mismo estaba afectado de una improvisación sin nombre, impensable cuando la Oficina del Alto Comisionado para la Paz tiene una estructura organizacional digna de un Ministerio. Una lectura más realista es la que sostiene que las omisiones en que se incurrieron fueron planeadas y lo fueron porque el gobierno no estaba dispuesto a llevar a cabo la investigación y el juzgamiento de los paramilitares o bien no podía hacer ninguna de las dos cosas. Ello, finalmente, significó el pago de un elevadísimo costo en términos de impunidad y un déficit irrecuperable de verdad, justicia y reparación. A lo anterior debe agregarse la poco significativa capacidad del poder judicial para investigar y juzgar una inmensa cantidad de hechos delictivos; siendo ya un distintivo de la jurisdicción ordinaria su estructural déficit de recursos, éste resulta multiplicado en la jurisdicción de Justicia y Paz; esta situación, de por sí puede constituir una demora injustificada en el juicio, a la luz del literal $b$ del numeral 2 del artículo 17 del Estatuto de la Corte. Si a ella se agrega los reducidos tiempos en que se debe adelantar el proceso, puede estarse configurando, además, una falta de disposición de llevar a cabo la investigación y el juzgamiento. La verdad - uno de los ejes alrededor de los cuales gira la Ley 975 de 2005 - tampoco saldrá favorecida con los procesos penales seguidos a los paramilitares elegidos por el Gobierno Nacional; además de que la verdad concierne exclusivamente al que rinde la versión, no existe modo alguno de llegar a saber cómo funcionó la estructura paramilitar, ni quienes apoyaron, auxiliaron y promovieron dichas estructuras; 
el silencio de uno o más de los delitos cometidos no tiene consecuencias relevantes sobre el versionado. Este aserto ya está teniendo constatación empírica: Un jefe paramilitar del Magdalena Medio, ha negado, en su versión ante los delegados de la Fiscalía General de la Nación, su autoría en delitos de secuestro, desapariciones, masacres, ejecuciones sin fórmula de juicio, desplazamientos forzados, despojos de propiedades, entre otros, pues sostiene que únicamente cumplía tareas de índole política; tal versión no deja de ser grotesca: Es, por decir lo menos, inadmisible afirmar ser ajeno a las decenas de los hechos abominables citados, estando al frente de ejércitos compuestos por cientos de hombres, en regiones donde él era el único poder existente, con la complacencia de no pocos agentes del Estado. El ocultamiento de la verdad, viene aparejada con el esguince que se le hace a la exigencia de reparación, otro de los ejes de la Ley; como ya quedó señalado esta obligación de los paramilitares se pretende derivar a los contribuyentes. A pesar de su versión inverosímil, tal jefe paramilitar continúa vinculado a la jurisdicción de Justicia y Paz, sin que se haya examinado la posibilidad de que sea juzgado por los tribunales ordinarios, con normas penales también ordinarias; ni siquiera se ha insinuado el aumento de la sanción dentro del marco de la pena alternativa. Tal panorama parece dar razón a quienes motejan a la Ley de Justicia y Paz de estar diseñada a la medida de los jefes paramilitares: Que buscaría un marco jurídico orientado a su sustracción de la responsabilidad penal de los jefes paramilitares, por crímenes de competencia de la Corte Penal Internacional.

La pena alternativa prevista en los artículos 3,11 y 29 , entre otros, de la Ley 975 de 2005, además de estar prevista para ser aplicada solamente a las personas elegidas por el Gobierno $\mathrm{Nacional}^{23}$, es la que más censuras ha recibido; ellas se fundamentan en que los crímenes en que han incurrido los paramilitares, son de tal gravedad que resulta ser de una desproporción, que raya con la arbitrariedad, la previsión de una pena máxima de 8 años, que en la práctica será mucho menor; el beneficio acordado a los jefes paramilitares que el Gobierno escoja, solo perseguiría sustraerlos de la competencia de la Corte. Por lo demás, esta condena, por lo ridícula, está lejos de cumplir con los fines preventivos que debe perseguir la pena en el estado actual de nuestra cultura jurídica; las personas favorecidas con la pena alternativa no se sentirían motivadas a no repetir las conductas delictivas cometidas, mientras que las que fueron ajenas a los hechos pueden recibir el mensaje perverso de que el crimen paga y ser estimuladas a emularlas.

23 La parte final del artículo 11 de la Ley 975 de 2005 establece que "Solamente podrán acceder a los beneficios previstos en esta ley, las personas cuyos nombres e identidades presente el Gobierno Nacional ante la Fiscalía General de la Nación".
La hipótesis de que la publicitada desmovilización y la consiguiente promulgación de la Ley de Justicia y Paz, fue pensada a la medida de los intereses de los paramilitares, con el objeto de sustraerlos de la Competencia de la Corte Penal Internacional, parece verse corroborada, además, con los hechos ocurridos el día 13 del mes de mayo de 2008. Ese día fueron extraditados a los Estados Unidos 14 jefes paramilitares, para que respondan por delitos de narcotráfico. Este hecho, aparentemente normal dentro de la política de los gobiernos norteamericano y colombiano, no lo es tanto si se mira a la luz del contexto en que aconteció: Para ese momento estaba en la cúspide del debate interno, entre otras cuestiones, la sistemática negativa de los paramilitares, que habían rendido su versión ante los delegados de la Fiscalía General de la Nación, a reconocer sus delitos, 1; también lo estaban las próximas testificaciones de dichos individuos ante la Corte Suprema de Justicia, en los procesos de la denominada parapolítica, en los que se avizoraba iban a implicar a más personajes de la vida nacional, como propiciadores del paramilitarismo. El Gobierno Nacional, con el argumento de que los jefes paramilitares continuaban delinquiendo desde la prisión, los entregó a los Estados Unidos. Tal excusa es poco verosímil, pues si eso hubiese sido cierto, lo correcto era hacerles perder los beneficios de la pena alternativa y trasladarlos a la jurisdicción ordinaria, además de denunciar ante las autoridades competentes la comisión de esos nuevos delitos. Nada de eso sucedió: No se denunció la posible comisión de los nuevos delitos y tampoco se les excluyó de la Jurisdicción de Justicia y Paz; es más, el Gobierno manifestó que la reclamación de las víctimas se facilitaría en los Estados Unidos; esta última cuestión desafía las más elementales reglas de la experiencia y del sentido común. La propia Corte Suprema de Justicia de Colombia encontró que la justificación del Gobierno era insatisfactoria y, por ello, le solicitó explicaciones, que hasta la fecha no han sido conocidas. El indicio más irrebatible de que con la decisión de entregar los jefes paramilitares a los Estados Unidos, se busca sustraerlos de la competencia de la Corte, radica en que, incurriendo en la más crasa desproporción, se trastoca la jerarquía de los bienes jurídicos en juego, y se prefiera el juzgamiento por un delito de tráfico de drogas, en vez de hacerlo por los de Lesa Humanidad; con el agravante de que en los Estados Unidos tienen la posibilidad de negociar la sanción.

\section{Conclusión}

En Colombia existe un conflicto armado interno, en el que, desde hace más cuarenta años, han participado y participan una diversidad de actores, que - en el espectro político - se ubican desde las extremas izquierdas hasta las derechas más radicales; a estos actores deben sumarse los estatales, cuyas acciones no siempre han estado suficientemente diferenciadas de los actores de la derecha a ultranza. En el desarrollo del 
conflicto se ha llegado a un estado de tan alta degradación, que los ataques generalizados y sistemáticos a la vida de las personas - muchos de ellos sin relación alguna con el conflicto armado -, se han convertido en moneda corriente; estos actos atroces se adecuan a los crímenes de lesa humanidad y de guerra, previstos en los artículos $7^{\circ}$ y $8^{\circ}$, respectivamente, del Estatuto de Roma de la Corte Penal Internacional; en Colombia, sin embargo, solo se podrán investigar y juzgar los crímenes de guerra, cuando se cometan después de que hayan transcurrido siete años contados a partir de su entrada en vigor, en razón de que el Estado colombiano ejerció su derecho a acogerse al artículo 124 del Tratado.

El estudio contrastado del Estatuto de la Corte Penal Internacional con la Ley 975 de 2005, denominada Ley de Justicia y Paz, parece vislumbrar que esta última busca, entre otras cosas sustraer a los jefes paramilitares de la competencia complementaria de la primera con el instituto procesal de la cosa juzgada. Adicionalmente, debe señalarse que la mayoría de la tropa paramilitar no fue seleccionada por el Gobierno para ser escuchada por los fiscales y jueces de la jurisdicción de Justicia y Paz; con ello se estaría admitiendo que no se quiere o bien que no se puede adelantar proceso penal alguno en contra de personas que con seguridad han cometido delitos de competencia de la Corte Penal Internacional, pues es inimaginable que los desplazamientos forzados, las masacres, las torturas, los delitos sexuales, las desapariciones forzadas, entre otros graves delitos - muchos de ellos sin relación alguna con el conflicto armado interno -, fueron materialmente cometidas únicamente por un puñado de señores de la guerra. El Estatuto de la Corte, sin embargo, ha previsto la posibilidad de que se recurra a estas perversas argucias, pues en sus artículos 20 y 17, prescribe que su competencia se activará, en los casos que el proceso se haya llevado a cabo con la intención de sustraer a las personas de su responsabilidad penal por crímenes confiados a su conocimiento, o cuando el Estado, en cuya jurisdicción se haya cometido el delito, no esté dispuesto o no pueda investigar y/o juzgar el delito, respectivamente. De las reflexiones realizadas en este estudio, se sigue que los presupuestos para la activación de la competencia complementaria de la Corte, para conocer de los Crímenes de Lesa Humanidad, están cumplidos y que su intervención para conocer de los hechos ocurridos en Colombia es solamente cuestión de tiempo.

\section{Referencias}

Álvarez, S. (2007). Derecho Internacional Público. Bogotá. Pontificia Universidad Javeriana.

Bergsmo, M (1999). El régimen de la competencia de la Corte Penal Internacional, en AAVV, El Estatuto de Roma de la Corte Penal Internacional. Traducción de Oscar Julián Guerrero Peralta. Edición a cargo de Kai Ambos y Oscar Julián Guerrero Peralta. Bogotá: Universidad Externado de Colombia.

Bull, H. (2005). Teoría internacional: en defensa del enfoque clásico, en AAVV, Relaciones Internacionales. El pensamiento de los clásicos. Edición a cargo de John A. Vásquez. México, D.F.: Editorial LIMUSA S.A.

Burton, J (2005). ¿Relaciones internacionales o sociedad mundial?, en AAVV, Relaciones Internacionales. El pensamiento de los clásicos. Edición a cargo de John A. Vásquez. México, D.F.: Editorial LIMUSA S.A.

Corte Penal Internacional. Estatuto De Roma De La Corte Penal Internacional.

Del Arenal, C (2005). Introducción a las Relaciones Internacionales. Madrid: Editorial Tecnos.

Devis Echandia, H. (1987) Compendio de Derecho Procesal. Teoría General del Proceso, Tomo I, 12ª Edición. Bogotá: Biblioteca Jurídica Diké.

Jarasch, F. (1999) Establecimiento, organización y financiamiento de la Corte Penal Internacional y cláusulas finales (partes I, IV, y XI a XIII), en AAVV, El Estatuto de Roma de la Corte Penal Internacional. Traducción de Mónica Karaján. Edición a cargo de Kai Ambos y Oscar Julián Guerrero Peralta. Bogotá: Universidad Externado de Colombia.

Kant, I (2005). Sobre la paz perpetua. Traducción de Joaquín Abellán. Madrid: Editorial Tecnos. 
Gonzalez Cussac, J y Gorriz Royo, E (2003). Ne bis in idem y determinación de la pena en el Estatuto de la Corte Penal Internacional, en AAVV, La Corte Penal Internacional (Un estudio interdisciplinar). Edición a cargo de Juan Luis Gómez Colomer, José Luis González Cussac y Jorge Cardona Lloréns. Valencia: tirant lo blanch tratados.

Kaul, H (1999). La Corte Penal Internacional: la lucha por su competencia y su alcance, en AAVV, El Estatuto de Roma de la Corte Penal Internacional. Traducción de Oscar Julián Guerrero Peralta. Edición de Kai Ambos y Oscar Julián Guerrero Peralta Bogotá: Universidad Externado de Colombia.

Kelsen, H. (2003) Teoría Pura del Derecho. 2a Ed., 1960. Traducción de Roberto Vernengo. México D.C.: Editorial Porrúa.

Pardo Rueda, R (2007). Fin del paramilitarismo. ¿Es posible su desmonte? Bogotá: Ediciones B. Colombia S.A.

Pérez, M (2003) La Organización y competencia de la Corte Penal Internacional, en AAVV, La Corte Penal Internacional (Un estudio interdisciplinar). Edición a cargo de Juan Luis Gómez Colomer, José Luis González Cussac y Jorge Cardona Lloréns. Valencia: tirant lo blanch tratados.

República de Colombia (2005) Ley de Justicia y Paz o Ley 975 de 2005.

República de Colombia (2002) Ley 742 del 5 de junio de 2002.

República de Colombia (2002) Corte Constitucional. Sentencia C-578/02 del 30 de julio de 2002.

Santalla, E. (2007) Contribución de Bolivia a AAVV, Dificultades jurídicas y políticas para la ratificación o implementación del Estatuto de la Corte Penal Internacional. Edición a cargo de Kai Ambos, Ezequiel Malarino y Jan Woischnik. Bogotá: Editoriales Duncker \& Humblot, Konrad Adenauer-Stiftung y Temis.

Schmitt, C. (1970) Teoría de la Constitución. 1927. Introducción de Francisco Ayala. México D.F.: Editora Nacional.

Schünemann, B. (2007) ;El derecho penal es la última ratio para la protección de bienes jurídicos! Sobre los límites inviolables del derecho penal en un Estado liberal de derecho. Traducción de Ángela de la Torre Benítez. Bogotá: Universidad Externado de Colombia.

Vásquez, J (2005). Matiz a la Morgenthau: pruebas recientes a una añeja tesis de política internacional cuantitativa, en AAVV Relaciones Internacionales. El pensamiento de los clásicos. Edición a cargo de John A. Vásquez. México D.F.: Editorial LIMUSA S.A.

Vidales, C. (2003). El principio de legalidad en el Estatuto de la Corte Penal Internacional, en AAVV, La Corte Penal Internacional (Un estudio interdisciplinar). Edición a cargo de Juan Luis Gómez Colomer, José Luis González Cussac y Jorge Cardona Lloréns. Valencia: tirant lo blanch tratados. 